\title{
IPI Score 0-1
}

National Cancer Institute

\section{Source}

National Cancer Institute. IPI Score 0-1. NCI Thesaurus. Code C161646.

A score of 0 or 1 on the International Prognostic Index indicating that an individual has a low risk of progression of non-Hodgkin lymphoma and a 5 year survival of $73 \%$. 